7. Бухтарминские старообрядцы : [сб. ст.] / ред. С. И. Руденко.-Москва : Изд-во Акад. наук СССР, 1930. - 460 с. - (Академия наук Союза Советских Социалистических Республик : Материалы комиссии экспедиционных исследований ; Вып. 17 : Серия Казахстанская).

8. Гришанова, Т. В. Этнографические материалы Н. Н. Нагорской в коллекциях Новосибирского государственного краеведческого музея : каталог / Т. В. Гришанова, С. О. Куимова, Т. И. Лисиенко [и др.] ; редкол. : И. В. Орлова [и др.]. - Новосибирск : Новосибирский гос. краеведческий музей, 2008. - 120 с.

\author{
Albina $V$. Bogochanova \\ State Art Museum of Altai Krai (Barnaul, Russia) \\ bogochanoff@mail.ru
}

\title{
EFFORT OF EXPLANATION OF SOVIET RUSSIA'S ETHNOGRAPHIC HERITAGE OF THE 1920S
}

\begin{abstract}
The paper considers some tendencies appeared in Soviet ethnographic science in 1920s after acceptance by young Soviet state a new political line in inter-ethnic relation issues named "localization policy" or "indigenisation" in Russian historiography. The author's conclusions are based on analysis of the Academy of Sciences of the Soviet Union's scholars' subject-matter key writings and reports of major ethnographic fieldworks started by special expert committees opened in major Soviet ethnographic museums at the first quarter of the $20^{\text {th }}$ century. On the author's opinion, increased research activities of Soviet scientific forces in the object field of ethnographic science is an answer to a governmental order for elaboration of theoretical base for meeting ideological goals in so called "ethnic building" area; the article gives a number of examples of ethnographic fieldworks with indigenous people (Altaians, Bachat Teleuts) from Altai Mountains (former Oirot autonomous region, now the Altai Republic).

Keywords: ethnography, Russian Ethnographic School, field ethnographic research, peoples of Soviet Russia, ethnic groups of Altai Mountains territory (Oirot autonomous region), Altaians, Bachat Teleuts, Soviet localization policy (indigenisation), culture and way of life of indigenous people, museum collections.
\end{abstract}

УДК 910.4Шерр“1898”:37(571.1/5)(=512.1)

DOI: $10.32340 / 2414-9101-2020-4-33-38$

С. И. Бондаренко кандидат исторических наук, доцент Алтайский государственный аграрный университет (Барнаул, Россия) bonsvet@bk.ru

\section{ХОЗЯЙСТВЕННЫЕ И КУЛЬТУРНЫЕ ТРАДИЦИИ КУМАНДИНЦЕВ ПРЕДГОРНОГО АЛТАЯ В ТРУДАХ Н. Б. ШЕРРА}

\begin{abstract}
Аннотация. Охарактеризованы некоторые аспекты хозяйственных и культурных традиций одного из коренных малочисленных народов России, относящегося к группе северных алтайцев в составе тюрской этноязыковой общности - кумандинцев. На основе этнографических записок рубежа отечественного политссыльного, исследователя-энтузиаста Н. Б. Шерра (1867 - ? гг.) автор статьи описывает базовые элементы культуры жизнеобеспечения кумандинцев XIX-XX вв. - жильё, пищу, одежду, характеризует ряд особенностей земледельческого труда, собирательства, скотоводства, ловчих промыслов, охоты, выделяет ряд особенностей культуры хозяйствования кумандинцев: доминирование промысловых видов деятельности (ореховый, белковый), слабое развитие сельскохозяйственной деятельности (земледелие, огородничество). По наблюдениям Н. Б. Шерра, большое влияние на развитие видов промысла и традиций хозяйствования кумандинцев оказали русские переселенцы.

Ключевые слова: кумандинцы, этнография кумандинцев, северные алтайцыь, Алтай, традиции, культура, Н. Б. Шерр, хозяйственная культура, промысль, торговля, пища, огородничество, верования.
\end{abstract}


Труды ученых, путешественников, общественных деятелей XVIII в. - начала XX вв. являются уникальным историческим источником для всестороннего изучения быта, традиций культуры народов Алтая. Они оставили свои наблюдения, исследования, которые позволяют нам увидеть авторские впечатления, эмоционально окрашенные оценки, уникальную интерпретацию исторических фактов. Эти источники позволяют более точно реконструировать образы автохтонного населения в контексте их восприятия современниками.

Одним из таких исследователей, оставившем ценные наблюдения об одном из коренных малочисленных народов России - кумандинцах, является Николай Борисович Шерр. Он, будучи учителем в Петербурге, был выслан за революционную пропаганду в Сибирь, а в 1880-1890 гг. он проживал в Барнауле и занимался сельскохозяйственной статистикой. Интересы Н. Б. Шерра были весьма разносторонни. По поручению Общества исследователей Алтая он совершает экспедицию в предгорья Алтая. Там он знакомится с малочисленным народом Сибири - кумандинцами. В течение двух месяцев он посещает кумандинские аилы, Турочак, Улалу. Исследователь тщательно изучает быт, традиции, природные условия проживания кумандинцев. Собранные материалы исследователь публикует в 1903 г. в пятом томе «Алтайского сборника» под названием «Из поездки к кумандинцам в 1898 году».

Интерес Н. Б. Шерра к особенностям хозяйствования и культуре кумандинцев объясним. Кумандинцы являются одной из этнических групп северных алтайцев. Ими была создана специфическая культура, позволившая им адаптироваться к природным условиям северного предгорья Алтая и сохранить свою идентичность, несмотря на многочисленные социальные катаклизмы. Н. Б. Шером были исследованы и описаны различные элементы культуры жизнеобеспечения - жилье, пища, одежда и способы их обеспечения - трудовые традиции, в т. ч. земледелие, собирательство, скотоводство, ловчие промыслы, охота. Это позволяет выделить ряд особенностей культуры хозяйствования этноса.

По описанию Н. Б. Шерра кумандинцы проживали в Бийском уезде в двух - Верхне- и НижнеКумандинских волостях, которые не представляли собой замкнутой территории, с определенными границами, так как их аилы были разбросаны по нескольким русским и инородческим волостям и управам [1, с. 324].

Территория, которую посетил исследователь, была заселена русскими крестьянами - сибиряками и переселенцами, а также кумандинцами. Также встречались казаки, мещане и оседлые инородцы Быстрянской управы. Из кочевников исследователь выделяет черневых татар. Говоря о составе населения, Н. Б. Шерр замечает, что термины «оседлый» и «кочевой» уже потеряли свой буквальный смысл в данной области, поскольку истинных кочевников в рассматриваемый исследователем период уже практически не существовало.

Кумандинцы избегали жить в одиночку вне аилов. В среднем селение насчитывало около 10 хозяйств, селение покрупнее насчитывало 50-60 хозяйств. Жители аила составляли общество и решали общие дела сходом. Для участия в сходах, как и в других общественных делах, существовал предельный возраст, от 18 до 50 лет. Сход мог допускать на собрания и стариков выше предельного возраста, если признавалось, что житель достоин участия в общественных делах.

Для выбора на общественные должности не существовало имущественного ценза, но на должность, связанную с хранением или сбором общественных денег, выбирали бедняка, только если его честность, его бескорыстие были общеизвестны и не вызывали, ни у кого сомнения. Вопросы, касающиеся общества, разрешались его членами на сходе, для проведения которого необязательно было даже присутствие кого-либо из выборных обществом начальствующих лиц. Но в случаях возникновения спора, невозможности вынести определенное решение, или необходимости его оформления, а также в случае, если в спорном вопросе был замешан кто-либо из членов другого аильного общества, необходимо было участие и председательствование представителя рода.

Аил представляет собою небольшое селение с неправильно разбросанными постройками. В чисто кумандинских аилах не было улиц в смысле выдержанных линий или рядов построек. Преобладающим типом построек являлась изба, т. е. четырехстенное строение в одну комнату с русской печью, сбитой из глины.

Основными занятиями кумандинцев являлись, скотоводство, пчеловодство, рыболовство и ореховый и белковый промыслы. Все остальное, как наем на страду к крестьянам, извоз и т. п., играло весьма незначительную роль. Запашка производилась пропорционально потребностям своей семьи. 
На рынок в небольших размерах шел иногда овес. Скот кумандинцы держали преимущественно крупный - лошадей, коров. Количество мелкого скота было весьма невелико.

Основой питания кумандинской семьи являлось мясо лошадей, реже коров, молоко, мед, рыба. На продажу шло масло, часть мяса, мед. Главную роль в обеспечении кумандинской семьи денежными средствами являлись ореховый и белковый промыслы.

Бить орех отправлялись целыми семьями в середине августа. Продолжительность промысла составляла месяц, иногда полтора.

Прибыв на место, строили из пихтовых жердей шалаши (одар) и разводили костры. Продукты питания привозили с собой. Орудия для битья орехов привозили с собой, но чаще всего на дерево взбирались «лазаки». Они сбивали шишки с помощью длинного шеста-прогона или просто трясли ветки [3, с. 70]. Сдавали орех в основном перекупщикам, которые его сушили, а с началом января поставляли на ярмарки.

После Покрова кумандинские мужчины ходили на белку. Охота обычно продолжалась до наступления зимы. Эти два промысла, по сути, и кормили кумандинцев. При хорошем урожае ореха и обилии белки, кумандинская семья зарабатывала 100-200 и более рублей за сезон.

Однако, в конце XIX в. ввиду быстрого заселения территории и распространения заимочного хозяйства кедровники стали исчезать достаточно быстро. Это привело к тому, что русские стали вытеснять инородцев. Конкуренция становилась все более острой. Одновременно развивалось посредничество в сбыте продуктов промысла, ссуды денег и предметов первой необходимости под будущую добычу, привоз товаров, а с ними и водки на место орехового промысла. Все это постепенно ухудшало экономическое положение кумандинцев.

Грабительский характер торговых операций отмечали и другие исследователи (Н. М. Яндринцев, М. А. Брещинский) [2, с. 318]. Вместе с тем, необходимо отметить, что, несмотря на грабительский характер торговли, русские переселенцы способствовали развитию некоторых промыслов. Так бортничество, имевшее чисто потребительское значение с приходом русских развилось в пасечное пчеловодство. Инструменты пчеловодства были такие же, как и русских крестьян [4, с. 2].

Официально, в делопроизводственных бумагах того времени влияние русских на жизнь аборигенов рассматривалось как способ перехода коренного населения Сибири на новую цивилизованную ступень. Так чиновник А. Вознесенский, исследовавший экономическое и правовое положение «инородцев» Нижне-Кумандинской волости пришел к выводу, что «в нижне-кумандинце умер наивный дикарь - дитя природы ... и нарождается новый сельский хозяин по образцу его учителя - сибирского крестьянина» [2, с. 326]. Н. Б. Шерр также отмечал достаточно быструю ассимиляцию кумандинцев с русскими и даже высказывал опасение об исчезновении кумандинцев как этнографического типа.

Сравнивая особенности хозяйствования и быта русских и кумандинцев, мы можем увидеть много общего. Так, бревенчатые стены, проложенные мхом, или промазанные глиной, иногда выбеленные, небольшие окна, встречаются и у русских поселенцев. Внутреннее убранство жилища также сравнимо с убранством русской избы.

Традиционную обстановку кумандинского жилища составляли полати или нары, лежанка у печи, широкие скамьи для сиденья или сна. Так же встречались небольшого размера скамьи, передвигающиеся по мере надобности. Присутствие табуретов, стульев, деревянных диванов определенным образом характеризовало ту или иную степень культурности данной семьи, но не всегда. Более разнообразная мебель, например, шкаф, комод, кровать и т. п., встречалась реже - только у самых состоятельных и более культурных семей. Сундук (а нередко и несколько сундуков), на котором днем были сложены кошмы и подушки, встречались в большинстве жилищ. Кошмы являлись необходимыми предметами, и служили подстилкой для сна. Подушки в беднейших семьях использовались редко и заменялись чем-нибудь другим.

Для освещения своего жилища кумандинцы использовали керосиновую лампу, сальные свечи, и «каганец». Керосиновая лампа с каждым годом получала все большее распространение, но каганец продолжали использовать. Каганец представлял собой простой светильник. Кусок сала или фитиль помещался на какой-нибудь черепок от сломанной крынки, и каганец был готов к использованию.

Практически обязательным атрибутом жилища рассматриваемой этнической общности являлось ружье - важное промысловое орудие кумандинцев. Если в семье было несколько промысловых 
охотников, у каждого имелось свое ружье. В основном были распространены дешевые пистонные винтовки, реже - такие же двустволки, но встречались и архаические кремневые ружья с необходимым для стрельбы приспособлением - рогаткой или подставкой. Кумандинец, для которого промысловая охота составляла один из важнейших ресурсов жизнеобеспечения, весьма охотно отказывался от кремневого ружья в пользу дешевой винтовки, стреляющей на 30-50 шагов, и являющейся простой и удобной в обращении.

Во второй половине XIX в. ружья становятся более доступны инородцам ввиду низкой цены (6-8 руб. для винтовки и 12 руб. для дробовика - двустволки). Торговлей ружьями занимались татары и русские. Также ружья можно было приобрести в Бийске, Улале и в других крупных русских селениях. Иногда ружья обменивали на орех. Из других промысловых орудий можно назвать ловушку для колонка.

Важной составляющей рациона кумандинцев являлась рыба, поэтому практически в каждой семье имелись рыболовные снасти, ничем не отличающиеся от русских рыболовных снарядов. Земледелие также было распространено среди кумандинцев, хотя и в небольших размерах. Практически все земледельческие орудия были заимствованы у русских.

Шерр выделяет только одну особенность кумандинского хозяйства, являющуюся результатом, по его мнению, во-первых, более позднего возникновения у них земледелия, во-вторых, сравнительной незначительностью эксплуатируемых земельных участков, в-третьих, второстепенностью этого промысла и, в-четвертых, меньшей хозяйственной культурностью кумандинцев. Эта особенность состояла в том, что у кумандинцев земледельческие орудия были значительно примитивнее, чем у русских крестьян.

В это время русские переселенцы уже активно использовали плуги и усовершенствованные сохи. Кумандинцы использовали самую простую соху. У русских молотьба осуществлялась лошадьми; у кумандинцев - цепами и сучковатыми толстыми палками с изгибом.

Переходя к пищевым традициям, можно отметить, что и в этой области кумандинцы в значительной степени усвоили русские традиции.

Из напитков кумандинцы предпочитали кирпичный чай. Его пили по несколько раз в день, с медом, с сахаром, с молоком, иногда со сметаной. По сравнению с русскими крестьянами квас практически не употреблялся. Из хлебных изделий кумандинцы употребляли пшеничный хлеб, который выпекался, как и у русских, в виде булок и калачей. Наряду с пшеничным, встречался и ячменный хлеб. Хлеб кумандинцы употребляли по сравнению с русскими более низкого качества. Это объяснялось, прежде всего, недостаточным умением выпекать его, и отчасти худшими сортами муки. Кроме хлеба, из муки пекли лепешки, блинчики и т. п. Хлеб и чай были главными продуктами питания.

Вторым по значимости продуктом питания можно назвать молоко. Также в пищу употреблялись яйца. Из них варили полужидкую похлебку, примешивая молоко. Из рыбы пекли грубые пироги, приготовляли похлебку. Из мясных продуктов употребляли мясо диких уток, диких козлов, домашней птицы, и другого домашнего скота. Мясо употреблялось в вареном виде, готовились похлебки, причем мясо проваривалось очень тщательно.

Но мясные продуты не часто оказывались на столе кумандинцев. Разведением домашней птицы кумандинцы занимались незначительно. Причем мясо петухов не употреблялось вообще, т. к. по мнению кумандинцев «он своим криком будил черта». Мясо диких птиц было сложно добыть, ввиду отсутствия охотничьих собак. Содержать же домашний скот было для кумандинцев достаточно дорого.

Преимущественно кумандинцы употребляли в пищу мясо нерабочих, старых лошадей, которых чаще всего покупали у русских поселенцев.

Что касается употребления говядины, обычно жители аила покупали вскладчину тушу и делили соразмерно внесенным средствам. Деньги отдавались либо сразу, либо осенью после промыслов. Также в пищу употребляли мясо зайца, белки. Не употребляли в пищу мясо колонка, медведя, свиньи. Кумандинцы употребляли в пищу мясо жертвенных животных при камлании, ими использовалась и соль, но они могли обходиться и без нее, особенно во время промыслов.

Кумандинцы в весьма незначительной степени занимались огородничеством. На полях выращивали небольшое количество картофеля и огурцов. Основные огородные культуры, широко 
распространенные у русских, практически не попадали на стол к кумандинцам. Такой пробел в списке пищевых продуктов был весьма чувствителен. Также и крупы играли незначительную роль в питании кумандинцев. Н. Б. Шерр замечает, что кумандинцы часто живут впроголодь, могут по нескольким месяцам питаться почти исключительно чаем с молоком, хлебом. Таким образом, по сравнению с русскими поселенцами питание кумандинцев было значительно менее калорийным, что объяснялось, прежде всего, неразвитостью земледелия у аборигенов.

Особого внимания заслуживают предметы быта кумандинцев. В каждом кумандинском жилище можно было встретить те же крынки, горшки, кочерги, деревянные чашки и ложки, и другие предметы домашнего обихода, какие были в каждой русской крестьянской семье. Туески разной величины, глиняная посуда, фарфоровые чайные чашки и блюдца тоже присутствовали. Самовар, как и у русских поселенцев, был весьма распространенным предметом домашнего обихода. В более состоятельных семьях самоваров было несколько, но в бедных семьях он отсутствовал, заменяясь более примитивными приспособлениями для чаепития. Широкое распространение самовара и чайной посуды свидетельствует о широком распространении традиции чаепития у кумандинцев.

Среди отличительных черт кумандинского характера Н. Б. Шерр отмечает общительность, робость, застенчивость, отсутствие злобы, мстительности кумандинцев, но вместе с тем отмечает и отсутствие живого темперамента и добродушия, гостеприимства, отсутствие в языке приветствий, пожеланий. «Развеселится кумандинец, в том смысле, в том духе, как веселится русский человек, сделается удалым, бойким, шутливым, готовым сплясать, и грянуть хором разудалую песню, так развеселиться кумандинец не может даже под влиянием винных паров» [1, с. 326]. Исследователь обращает внимание на отсутствие хоровых песен, постоянных мотивов и слов для песен.

В отличие от русской молодежи, кумандинская молодежь не имела традиций собираться в компанию для игр, песен, плясок. Если, где это и наблюдалось, то только под влиянием русских - в смешанных поселениях.

Относительно религиозных верований Н. Б. Шерр относит их религию к языческой, политеистической, так как кумандинцы признавали существование нескольких богов. Вместе с тем кумандинцы выделяли одного бога, как главного. По верованиям кумандинцев все, что могут совершить другие боги, заключается в пределах воли, желания и разрешения главного бога. Он позволяет другим богам действовать самостоятельно, по их воле, но всегда в его власти и силе остановить их.

Самым главным богом у кумандинцев считался Кок-Ульгень (синий бог), который сотворил все. За ним по иерархии следовал его помощник, помогавший ему при сотворении мира - Ак-Ульгень (белый бог). За ними шли по старшинству - Карлыс-каан, Тяжи-каан, Солтан-каан и Тяим-каан. Общепризнанными и одинаково у всех почитаемыми богами являлись первые два Ульгени. Отношение к младшим четырем - каанам было разным: одни больше почитали одного, другие другого. Все эти боги считались добрыми. Главным среди злых богов признавался Эрлик-улу-ада (отец злых духов).

Кроме двух указанных групп божеств в пантеоне присутствовали полубожества, одухотворяющие то, что играло значимую роль в жизни кумандинцев. Так, например, существовали духи: черни, гор.

В советский период многие культурные и хозяйственные традиции кумандинцев были в значительной степени утрачены. Однако, в конце 1980-х гг. был дан импульс возрождению национальных традиций. Это было связано с образованием Кумандинского национального совета и общественной организации «Возрождение кумандинского народа» [5, с 177]. В настоящее время кумандинский народ включен в список «Малочисленные народы Севера» и поддерживается государством, что способствует сохранению традиций кумандинского этноса.

\section{Список литературы}

1. Шерр, Н. Б. Из поездки к кумандинцам в 1898 г. // Алтай в трудах учёных и путешественников XVIII начала XX веков : [в 5 т.] / [сост. : В. А. Скубневский [и др.] ; редкол. : В. П. Кладова (отв. ред.) [и др.]. - Барнаул : АКУНБ, 2005-2014. - Т. 3. - 2009. - 305-328.

2. Историко-географические образы в трудах учёных, путешественников и чиновников XVIII - начала XX в. : моногр. / под ред. Т. Н. Соболевой, Д. С. Боброва. - Барнаул : Азбука, 2016. - 440 с. 
3. Байжуманова Н. К. К вопросу о промыслах в хозяйственном укладе кумандинцев предгорного Алтая в конце XIX - начале XX вв. // Этнография Алтая и сопредельных территорий : матер. междунар. науч.-практ. конф. (Барнаул, 29-30 сент. 2005 г.) - Барнаул : Изд-во Барнаульского гос. пед. ун-та, 2005. С. 70-71.

4. Карасева, Н. К. Бортничество кумандинцев предгорного Алтая в конце XIX-начале ХХ вв. // Фундаментальные исследования. - 2007. - № 8. - С. 1-5.

5. Кухтуекова, Н. В. Природные и социальные условия формирования и возрождения малочисленного этноса Сибири - кумандинцев // Социосфера. - 2013. - № 10. - С. 175-177.

Svetlana I. Bondarenko, Ph. D. in History, Associate Professor Altai State Agrarian University (Russia, Barnaul) bonsvet@bk.ru

\title{
ECONOMIC AND CULTURAL TRADITIONS OF KUMANDINS OF PIEDMONT ALTAI IN NIKOLAI SHERR'S WORKS
}

\begin{abstract}
The paper outlines some aspects of economic and cultural traditions of Kumandins who are one of indigenous people of Russia that is referred with North Altaians who fall under Turkic ethnic and linguistic community. The author of the article by using ethnographic writings made by Nukolai Sherr (1867?), a Russian political deportee and a researcher, describes basic elements of Kumandins of the $19^{\text {th }}$ and $20^{\text {th }}$ century, such as dwelling, food, clothes, names peculiarities of farming, gathering, cattle breeding, hunting, and highlights the next specifics of Kumandins' economic culture: dominance of harvesting, weak farming,. On Nikolai Sherr's notice, Russian settlers had a big effect of development of Kumandins' economic traditions.
\end{abstract}

Keywords: Kumandins, ethnography of Kumandins, North Altaians, Altai, traditions, culture, Nikolai Sherr, economic culture, catching, trading, food, vegetable gardening, beliefs.

УДК 72:[338.486:711.2]

DOI: $10.32340 / 2414-9101-2020-4-38-44$

Ю. С. Ананьева, кандидат химических наук Алтайский государственный педагогический университет (Барнаул, Россия) isan1963@yandex.ru

А. Г. Жаркова

Алтайский государственный технический университет им. И. И. Ползунова (Барнаул, Россия) madsheart@gmail.com

\section{АРХИТЕКТУРНЫЕ КОПИИ И ИСТОРИКО-КУЛЬТУРНЫЕ СТИЛИЗАЦИИ В ТУРИСТИЧЕСКОЙ СФЕРЕ}

\begin{abstract}
Аннотация. Рассмотрен состав факторов, определяющих возросшую популярность практик репликации архитектурных объектов, относящихся к категории памятников национального и мирового исторического и культурного наследия и привлекающих в этом качестве неизменный интерес потребителей услуг туристической сферы. В подтверждение своей точки зрения авторы ссылаются на многочисленные отечественные и зарубежные примеры создания копий приобретших всемирную известность сооружений, с разной степенью достоверности воплощающих характерные для архитектурных традиций той или иной культуры композиционные приёмы, художественные стили и декоративные мотивы. Кратко рассмотрены основные тенденции тиражирования архитектурных образцов традиционных культур в контексте инфраструктурного развития отечественных туристических локаций; изложены базовые аргументы сторонников и противников этого направления развития туристического сектора.
\end{abstract}

